\title{
PREVALENCIJA SIMPTOMA ALERGIJSKIH OBOLJENJA KOD DJECE ŠKOLSKOG UZRASTA U REPUBLICI SRPSKOJ
}

\author{
THE PREVALENCE OF SYMPTOMS OF ALLERGIC DISEASES AMONG SCHOOL CHILDREN IN \\ REPUBLIC OF SRPSKA
}

\author{
Sanela Domuz Vujnović, Adrijana Domuz, Slobodanka Petrović
}

\begin{abstract}
SAŽETAK: Naša studija je prva ovakva studija koja koristi internacionalnu metodologiju za određivanje prevalencije alergijskih oboljenja kod školske djece. Cilj ove studije bio je odrediti prevalenciju i geografske varijacije simptoma alergijskih oboljenja kod djece školskog uzrasta na teritoriji Republike Srpske. Istraživanje je provedeno u obliku studije presjeka i obuhvatalo je 3000 djece iz 13 osnovnih škola. Prevalencija simptoma alergijskih oboljenja određivala se putem upitnika Internacionalne studije za astmu i alergije kod djece (The International Study of Asthma and Allergies in Childhood-ISAAC).

Prevalencija vizing u poslednjih 12 mjeseci u Republici Srpskoj bila je 7,95\%, ekcema 5,01\% i simptoma alergijskog rinokonjuktivitisa 12,71\%. Simptomi astme najčešće su prisutni kod djece uzrasta od 8 do 10 godina. Prevalencija simptoma ekcema i alergijskog rinitisa ima tendenciju rasta do 9. odnosno 10. godine uzrasta djeteta, poslije čega se uočava pad učestalosti ovih simptoma.

Rezultati multicentričnih studija pokazuju da su zemlje u razvoju, kao što je naša, u posebnom riziku za veću učestalost simptoma alergijskih oboljenja kod djece. Stoga je važno provoditi epidemiološke studije o prevalenciji ovih oboljenja, posebno imajući na umu uticaj ovih oboljenja na kvalitet života djece.
\end{abstract}

Ključne riječi: astma; ekcem; alergijski rinitis; djeca; prevalencija; studije presjeka.

\section{UVOD:}

Alergijska oboljenja kod djece postaju jedan od vodećih zdravstvenih, socijalnih i ekonomskih problema $u$ svijetu. $^{1-3}$ Porast prevalencije ovih oboljenja kod djece koji je zapažen zadnjih 30-tak godina značajno opterećuje i zdravstvene sisteme, posebno zemalja u razvoju. ${ }^{1}$ Kvalitet života djece sa simptomima astme, alergijskog rinitisa ili ekcema značajno je smanjen posebno imajući na umu da ova alergijska oboljenja često imaju komorbiditet. ${ }^{1,4,5} \mathrm{U}$ pojedinim regionima uočen je dramatičan porast učestalosti alergijskih oboljenja, međutim tačan model kretanja prevalencije alergijskih oboljenja kod djece još nije jasno utvrđen. ${ }^{6,7}$ Značajan porast prevalencije simptoma alergijskih oboljenja kod djece djelimično je povezan $i$ sa promjenama $u$ načinu života i većem stepenu urbanizacije. ${ }^{1,4}$ Ovo je posebno značajno za zemlje u razvoju kao što je naša. Brzina promjene trenda kretanja prevalencije $u$ određenim područjima ukazuje da je malo vjerovatno da genetski faktori čine značajniji procenat $\mathrm{u}$ epidemiologiji alergijskih oboljenja kod djece. ${ }^{4}$ Životna sredina i stil života mogu predstavljati faktore koji doprinose porastu prevalencije simptoma alergijskih oboljenja kod osjetljive djece, pri čemu je plato ili vrh prevalencije vjerovatno određen genetskim potencijalom populacije određenog područja., ${ }^{3,4,6}$ Stoga su epidemiološka istraživanja značajna za razumjevanje prirode alergijskih oboljenja kod djece.

Mnoge zemlje su provele opsežne epidemiološke studije prevalencije simptoma alergijskih oboljenja kod djece. ${ }^{7-9}$ Naša studija je prva takva epidemiološka studija u Republici Srspkoj koja je koristila internacionalnu metodologiju. Cilj našeg istraživanja bio je odrediti prevalenciju i geografske varijacije simptoma alergijskih oboljenja kod djece uzrasta od 6 do 15 godina na teritoriji Republike Srpske. 


\section{METODE:}

Istraživanje je provedeno u obliku studije presjeka na teritoriji Republike Srpske i obuhvatilo je 7 gradova. Studija prevalencije simptoma alergijskih oboljenja kod djece uzrasta od 6 do 15 godina provedena je u periodu od juna do oktobra 2014.godine putem upitnika Internacionalne studije za astmu i alergije kod djece (The International Study of Asthma and Allergies in Childhood ISAAC). Upitnici su dizajnirani za potrebe multicentrične studije o prevalenciji alergijskih oboljenja kod djece.

Prije same distribucije upitnika organizovano je predavanje razrednim starješinama uključenih odjeljenja o samom istraživanju i alergijskim oboljenjima kod djece. Roditelji/staratelji djece uključene $u$ studiju su mogli tokom samog istraživanja da postave dodatna pitanja glavnom istraživaču putem telefona $\mathrm{i} / \mathrm{ili}$ elektronske pošte. $\mathrm{U}$ našem istraživanju upitnike su popunjavali djeca zajedno sa roditeljima. Popunjene upitnike učesnici studije dostavljali su u zatvorenoj koverti u matične škole. Sve koverte sakupljala je jedna osoba zadužena od strane glavnog istraživača tokom 4 nedelje od početka studije. U studiju nisu bila uključena djeca sa postavljenim dijagnozama hroničnih respiratornih oboljenja (bronhopulmonalna displazija, bronhiektazije, cistična fibroza i primarna cilijarna diskinezija), kao i djeca koja nisu imala potpisan informisani pristanak za učešće u studiji od strane roditelja/staratelja.

Za pregled deskriptivnih podataka izračunate su frekvencije i procenti. Prevalencija simptoma alergijskih oboljenja određena je kao procenat pozitivnih odgovora na pitanja o prisustvu vizinga, ekcema na tipičnim mjestima i simptoma alergijskog rinitisa (problemi sa kijanjem, curenjem iz nosa ili zapušenošću nosa praćenog svrabom ili suzenjem očiju) u poslednjih 12 mjeseci. Prilikom testiranja odnosa između pojedinih nezavisnih varijabli i prevalencije pojedinih simptoma alergijskih oboljenja korišten je Pirsonov hi kvadrat test. Pri određivanju statističke značajnosti rezultata za graničnu vrijednost je uzeta pouzdanost od 0,05 pri čemu se statistički značajnim smatrao rezultat pouzdanosti $p<0,05$. Podaci su analizirani uz pomoć statističkog softvera IBM SPSS Statistics 21.
Etička saglasnost za izvođenje ove studije dobijena je od Etičkom odbora Javne zdravstvene ustanove Institut za javno zdravstvo Republike Srpske.

\section{REZULTATI:}

U studiju je uključeno 3000 djece uzrasta od 6 do 15 godina na teritoriji Republike Srpske. Ukupna stopa odgovora ispitanika u studiji je 77,4\% (slika 1). U konačnu obradu ušlo je 1975 upitnika koji su pravilno popunjeni i kod kojih je na većinu pitanja odgovoreno. Osnovne karakteristike ispitanika prikazane su u tabeli 1 . Prosječna starost uzorka bila je 10,2 godine $(\mathrm{SD}=2,4)$.

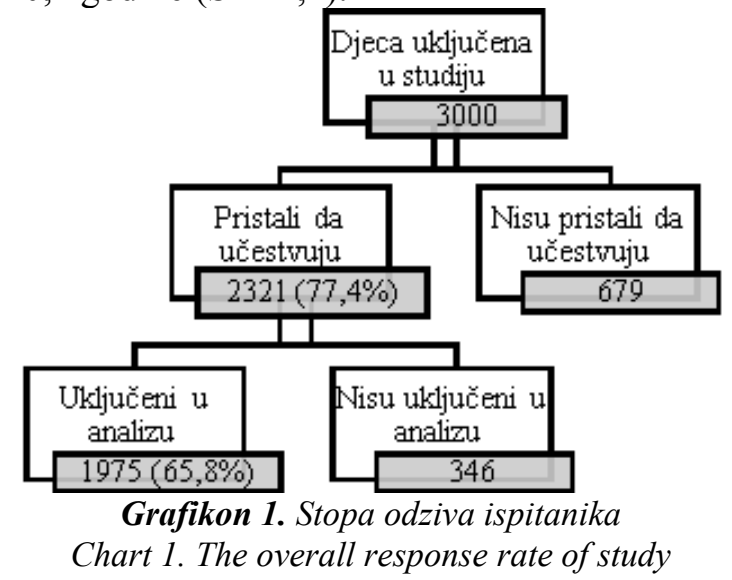

\begin{tabular}{lcc}
\hline Karakteristike ispitanika & $\mathrm{N}$ & $\%$ \\
\hline Uzrast & & \\
6 godina & 137 & 6,9 \\
7 godina & 185 & 9,4 \\
8 godina & 224 & 11,3 \\
9 godina & 247 & 12,5 \\
10 godina & 286 & 14,5 \\
11 godina & 215 & 10,9 \\
12 godina & 245 & 12,4 \\
13 godina & 223 & 11,3 \\
14 godina & 213 & 10,8 \\
Pol & & \\
dječaci & 935 & 47,3 \\
djevojčice & 1040 & 52,7 \\
Centar & & \\
Banja Luka & 306 & 15,5 \\
Bijeljina & 394 & 19,9 \\
Han Pijesak & 73 & 3,7 \\
Gacko & 123 & 6,2 \\
Bileca & 274 & 13,9 \\
Trebinje & 465 & 23,5 \\
Pale & 340 & 17,2 \\
\hline
\end{tabular}

Tabela 1. Karakteristike ispitanika uključenih u studiju Table 1. Selected characteristics of the study population 
Prevalencija vizing u poslednjih 12 mjeseci u Republici Srpskoj bila je 7,9\% (95\% CI 6,8-9,1). Ekcem na tipičnim mjestima (pregibi laktova, koljena, gležnjevi, butine, vrat, oko ušiju ili očiju) imalo je 5,0\% (95\% CI 4,1-5,9) djece uključene u studiju. Simptome alergijskog rinitisa imalo je $12,7 \%(95 \%$ CI 11,3-14,1) djece u Republici Srpskoj (tabela 2).

\begin{tabular}{lccc}
\hline Simptomi alergijskih oboljenja & $\mathrm{n}$ & $\%$ & $\mathrm{CI} 95 \%$ \\
\hline Vizing u poslednjih 12 mjeseci & 157 & 7,9 & $6,8-9,1$ \\
Vizing tokom ili poslije fizičke aktivnosti & 76 & 3,8 & $3,0-4,7$ \\
Suv kašalj tokom noći u poslednjih $12 \mathrm{mj}$ & 292 & 14,8 & $13,3-16,3$ \\
Ekcem u poslednjih 12 mjeseci & 165 & 8,3 & $7,2-9,5$ \\
Ekcem na tipičnim mjestima & 99 & 5,0 & $4,1-5,9$ \\
Simptomi alergijskog rinitisa & 462 & 23,4 & $21,6-25,2$ \\
u poslednjih 12 mj & 251 & 12,7 & $11,3-14,1$ \\
\hline Simptomi alergijskog rinitisa i konjuktivitisa &
\end{tabular}

Tabela 2. Prevalencija simptoma alergijskih oboljenja u Republici Srpskoj

Table 2. Prevalence of symptoms of allergic diseases in Republic of Srpska

Djeca iz Bijeljine (10,7\%) i Bileće $(9,5 \%)$ imala su statistički značajno veću prevalenciju vizinga u poslednjih 12 mjeseci u odnosu na djecu iz drugih gradova (tabela 3). Suv kašalj tokom noći u poslednjih 12 mjeseci češće su imala djeca iz Bijeljine i Trebinja u odnosu na svoje vršnjake iz drugih mjesta Republike Srpske $(p<0,05)$. Statistički značajna razlika u prevalenciji uočena je i za simptome alergijskog rinitisa (tabela 3).
Najnižu prevalenciju simptoma alergijskih oboljenja u Republici Srpskoj imala su djeca iz Gackog (tabela 3).

Simptomi astme najčešće su prisutni kod djece uzrasta od 8 do 10 godina. Prevalencija simptoma ekcema i alergijskog rinitisa ima tendenciju rasta do 9. odnosno 10. godine uzrasta djeteta, poslije čega se uočava pad učestalosti ovih simptoma (tabela 4).

\begin{tabular}{|c|c|c|c|c|c|c|c|c|c|c|c|c|c|c|c|}
\hline \multirow[t]{2}{*}{ Simptomi alergijskih oboljenja } & \multicolumn{2}{|c|}{ Banja Luka } & \multicolumn{2}{|c|}{ Bijeljina } & \multicolumn{2}{|c|}{ Han Pijesak } & \multicolumn{2}{|c|}{ Gacko } & \multicolumn{2}{|c|}{ Bileća } & \multicolumn{2}{|c|}{ Trebinje } & \multicolumn{2}{|c|}{ Pale } & \multirow[t]{2}{*}{$\mathbf{p}$} \\
\hline & $\mathrm{n}$ & $\%$ & $\mathrm{n}$ & $\%$ & $\mathrm{n}$ & $\%$ & $\mathrm{n}$ & $\%$ & $\mathrm{n}$ & $\%$ & $\mathrm{n}$ & $\%$ & $\mathrm{n}$ & $\%$ & \\
\hline $\begin{array}{l}\text { Vizing u poslednjih } \\
12 \text { mjeseci }\end{array}$ & 14 & 4,6 & 42 & 10,7 & 6 & 8,2 & 3 & 2,4 & 26 & 9,5 & 36 & 7,7 & 30 & 8,8 & 0,02 \\
\hline Vizing tokom ili poslije fizičke aktivnosti & 8 & 2,6 & 22 & 5,6 & 4 & 5,5 & 0 & 0 & 13 & 4,7 & 17 & 3,6 & 12 & 3,5 & 0,10 \\
\hline $\begin{array}{l}\text { Suv kašalj tokom noći u poslednjih } \\
12 \mathrm{mj}\end{array}$ & 42 & 13,7 & 74 & 18,8 & 12 & 16,4 & 3 & 2,4 & 34 & 12,4 & 84 & 18,1 & 43 & 12,6 & 0,00 \\
\hline $\begin{array}{l}\text { Ekcem u poslednjih } \\
12 \text { mjeseci }\end{array}$ & 34 & 11,1 & 36 & 9,1 & 7 & 9,6 & 3 & 2,4 & 20 & 7,3 & 39 & 8,4 & 26 & 7,6 & 0,13 \\
\hline Ekcem na tipičnim mjestima & 25 & 8,1 & 20 & 5,1 & 6 & 8,2 & 3 & 2,4 & 11 & 4,0 & 19 & 4,1 & 15 & 4,4 & 0,07 \\
\hline $\begin{array}{l}\text { Simptomi alergijskog rinitisa } \\
\text { u poslednjih } 12 \mathrm{mj}\end{array}$ & 70 & 22,9 & 120 & 30,5 & 19 & 26,0 & 19 & 15,5 & 49 & 17,9 & 114 & 24,5 & 71 & 20,9 & 0,00 \\
\hline $\begin{array}{l}\text { Simptomi alergijskog } \quad \text { rinitisa } \\
\text { konjuktivitisa }\end{array}$ & $\mathrm{i}_{39}$ & 12,7 & 54 & 13,7 & 6 & 8,2 & 12 & 9,8 & 26 & 9,5 & 75 & 16,1 & 39 & 11,5 & 0,10 \\
\hline
\end{tabular}

Tabela 3. Prevalencija simptoma alergijskih oboljenja prema gradovima uključenim u studiju

Tabel 3. The prevalence of symptoms of allergic diseases according to the cities included in the study

\begin{tabular}{|c|c|c|c|c|c|c|c|c|c|c|c|c|c|}
\hline gijskih oboljenja & 6 & 7 & 8 & & 9 & & 10 & & 11 & 12 & 13 & 14 & $\mathrm{p}$ \\
\hline & n $\%$ & $\mathrm{n} \%$ & & $\%$ & $\mathrm{n}$ & $\%$ & & $\%$ & n $\%$ & $\mathrm{n} \%$ & $\mathrm{n} \%$ & n $\%$ & \\
\hline $\mathrm{Viz}$ & 1710,8 & 148,9 & 19 & 12,2 & 18 & 11,5 & 24 & 15,3 & 1610,2 & 1710,8 & 1811,5 & 148,9 & 0,75 \\
\hline Viz & $4 \quad 5,3$ & 34,0 & 0 & & 13 & & 4 & 5,3 & 101 & 1013,2 & 13 & 1114,5 & 0,13 \\
\hline & 17,2 & 3512,0 & 39 & & 30 & & 53 & 18,2 & 3110 & 237,9 & 3411,6 & 268,9 & 0,05 \\
\hline Ekc & 159,1 & 1911,5 & 20 & 12 & 25 & & 21 & 17,7 & 1911,5 & 169,7 & 159,1 & 159,1 & 0,65 \\
\hline Ekc & 111,1 & 1212,1 & 13 & 1 & 19 & 1 & 13 & 13,1 & $9 \quad 9,1$ & $4 \quad 4,0$ & 1111 , & $7 \quad 7,1$ & 0,05 \\
\hline & 265,6 & 378,0 & & 0 & 59 & & & 2 & 5912,8 & 5712, & 571 & 4710 & 0,62 \\
\hline Simptomi alergijskog rinitisa i konjuktivitisa & 124,8 & 176,8 & & 9,2 & 31 & 1 & & 7,5 & 3313,2 & 3313 & 3212 , & 2610 & 0,33 \\
\hline
\end{tabular}


Tabela 4. Prevalencija simptoma alergijskih oboljenja u Republici Srpskoj prema uzrastu ispitanika

Table 4. The prevalence of the symptoms of allergic diseases in Republic of Srpska according to the age of the respondents

Iako dječaci u Republici Srpskoj imaju veću učestalost simptoma alergijskih oboljenja u odnosu na djevojčice, statistički značajna razlika uočena je samo za simptome povezane sa astmom (tabela 5).

\begin{tabular}{|c|c|c|c|c|c|}
\hline \multirow[t]{2}{*}{ Simptomi alergijskih oboljenja } & \multicolumn{2}{|c|}{ Djevojčice } & \multicolumn{2}{|c|}{ Dječaci } & \multirow[t]{2}{*}{$\mathrm{p}$} \\
\hline & $\mathrm{n}$ & $\%$ & $\mathrm{n}$ & $\%$ & \\
\hline Vizing u poslednjih 12 mjeseci & 69 & 6,6 & 88 & 9,4 & 0,02 \\
\hline Vizing tokom ili poslije fizičke aktivnosti & 31 & 3,0 & 45 & 4,8 & 0,03 \\
\hline Suv kašalj tokom noći u poslednjih $12 \mathrm{mj}$ & 137 & 13,2 & 155 & 16,6 & 0,03 \\
\hline Ekcem u poslednjih 12 mjeseci & 89 & 8,6 & 76 & 8,1 & 0,73 \\
\hline Ekcem na tipičnim mjestima & 51 & 4,9 & 48 & 5,1 & 0,81 \\
\hline Simptomi alergijskog rinitisa u poslednjih $12 \mathrm{mj}$ & 227 & 21,8 & 235 & 25,1 & 0,08 \\
\hline Simptomi alergijskog rinitisa i konjuktivitisa & 119 & 11,4 & 132 & 14,1 & 0,07 \\
\hline
\end{tabular}

Tabela 5. Prevalencija simptoma alergijskih oboljenja u Republici Srpskoj prema polu ispitanika

Table 5. The prevalence of the symptoms of allergic diseases in Republic of Srpska according to the gender of the respondents

\section{RASPRAVA:}

Rezultati naše studije u skladu su sa rezultatima studija drugih evropskih zemalja ${ }^{7}$, kao i zemalja iz okruženja. ${ }^{10-12}$ Vizing $u$ poslednjih 12 mjeseci $u$ Republici Srpskoj imalo je 7,9\% djece. Trend kretanja ovog simptoma u evropskim zemljama je od 9,7 do $15,2 \%{ }^{7,9}$ Sličnu prevalenciju simptoma astme imala su i djeca iz okruženja (Srbija, Hrvatska, Makedonija). ${ }^{10-12}$ Djeca u RS imala su nešto manju prevalenciju suvog kašlja tokom noći u poslednjih 12 mjeseci $(14,9 \%)$ u odnosu na djecu iz evropskih gradova. ${ }^{8}$ Učestalost simptoma alergijskog rinitisa udruženih sa svrabom ili suzenjem očiju (12,7\%) kod djece u RS bila je nešto veća u odnosu na njihove vršnjake iz okruženja $(5,8 \%$ do $7,1 \%) .{ }^{11,12}$

Studije o prevalenciji simptoma astme kod djece nisu pokazale ujednačene rezultate u pogledu učestalosti ovih simptoma prema polu. Naime, prema rezultatima studija provedenih u Albaniji, Poljskoj, Švedskoj i Španiji djeca mlađeg uzrasta generalno su imala veću prevalenciju simptoma astme. $^{8}$ Međutim, rezultati studija provedenih $\mathrm{u}$ Austriji, Belgiji, Njemačkoj i Italiji pokazuju da starija djeca imaju veću učestalost simptoma astme. ${ }^{8}$ Najveću prevalenciju u našoj studiji imala su djeca uzrasta 9 i 10 godina. Djeca mlađeg uzrasta (6/7 godina) u Republici Srspkoj imala su nešto veću prevalenciju vizinga $\mathrm{u}$ poslednjih 12 mjeseci $\mathrm{u}$ odnosu na stariju djecu (13/14 godina). Kada posmatramo prevalenciju simptoma alergijskog rinokonjuktivitisa i ekcema kod djece u RS, uočavamo suprotan obrazac. Naime, djeca mlađeg uzrasta imaju značajno manju učestalost simptoma ovih alergijskih oboljenja u odnosu na stariju djecu. Ovakvi rezultati u skladu su sa rezultatima studija provedenih u evropskim zemljama. ${ }^{8}$ Posmatrajući rezultate studija prevalencije alergijskih oboljenja provedenih u evropskim zemljama, može se uočiti da nema odstupanja u trendu kretanja prevalencije alergijskog rinitisa i ekcema $\mathrm{u}$ odnosu na uzrast djece između različitih centara. ${ }^{8}$

Dječaci uključeni u našu studiju imali su veću učestalost simptoma alergijskih oboljenja u odnosu na djevojčice. Rezultati dosadašnjih studija takođe pokazuju veću učestalost simptoma alergijskih oboljenja kod dječaka u odnosu na djevojčice. ${ }^{1,8,13,14}$ $\mathrm{U}$ adolescenciji se ove razlike gube, pa je u kasnijem životnom dobu astma učestalija kod osoba ženskog pola. ${ }^{1,13,14}$ Nema jednog jasno definisanog mehanizma koji može da objasni ovu razliku. Objašnjenja za ovakav trend kretanja prevalencije simptoma astme mogu biti različita. U literaturi se kao mogući faktori spominju genetske predispozicije, primjer je genski polimorfizam posebno karakterističan za astmu kod ženskog pola, zatim uži disajni putevi kod dječaka, povećan tonus disajnih puteva $\mathrm{i}$ veći nivo IgE antitijela kod djevojčica. ${ }^{1,15,16}$ Studije sugerišu da hormonalne promjene tokom djetinjstva i adolescencije mogu biti razlog razlike u prevalenciji simptoma alergijskih oboljenja kod dječaka i djevojčica. ${ }^{17}$ 
Smatra se da polni hormoni imaju važnu ulogu u razvoju i ishodu alergijskog imunog odgovora, posebno kod djece sa astmom. ${ }^{17}$

Razmatrajuči nedostatke epidemioloških studija, moramo naglasiti da slučajne greške zbog nepreciznosti definicija alergijskih oboljenja (astme, alergijskog rinitisa i ekcema) nije moguće izbjeći. Korištenjem internacionalne metodologije i ISAAC upitnika za definiciju simptoma alergijskih oboljenja kod djece nastojali smo ovu grešku svesti na minimum. Pošto je cilj studije bio odrediti prevalenciju simptoma alergijskih oboljenja kod djece uzrasta od 6 do 15 godina, izabrani uzorak jeste reprezentativan za izabranu ciljnu grupu iz opšte populacije. Izborom što većeg broja ispitanika smanjuje se vjerovatnoća nastanka slučajne greške uzorkovanjem u epidemiološkim studijama. U ovu studiju bilo je uključeno 1975 djece uzrasta od 6 do 15 godina, što smanjuje mogućnost nastanka navedene greške.

Sistemske greške pristrasnosti usled izbora $u$ epidemiološkim studijama značajno umanjuje veći odziv ispitanika. Stopa odziva u našoj studiji bila je $77,4 \%$ što se može smatrati zadovoljavajućim odzivom. ${ }^{18,19}$ Nediferencijalnu informacionu pristrasnost $u$ studiji nije bilo moguće izbjeći pošto su upitnike popunjavali roditelji/staratelji djece uključene $u$ studiju, te je njihovo vjerovanje i shvatanje simptoma iz upitnika uticalo na određivanje prevalencije simptoma alergijskih oboljenja kod djece. Pristrasnost u epidemiološkim studijama usled pridruženosti umanjena je isključivanjem djece sa drugim hroničnim respiratornim oboljenjima koja su praćena vizingom.

\section{ZAKLJUČAK:}

Ova studija ima naučni i javno-zdravstveni značaj. Rezultati naše studije pokazuju da djeca iz određenih sredina na teritoriji Republike Srpske imaju veću učestalost simptoma alergijskih oboljenja. Stoga se metodologija našeg istraživanja i ISAAC upitnik može primjeniti u prvoj fazi sekvencijalnog skrining programa na primarnom nivou zdravstvene zaštite, posebno u sredinama sa većom prevalencijom. Na ovaj način bi se definisala populacija djece koja bi zahtjevala dodatnu dijagnostičku obradu. Ranije prepoznavanje ove populacije djece omogućava preventivno djelovanje i raniji tretman u cilju potencijalne redukcije težine bolesti i posledica.

\section{LITERATURA:}

1. Ljuština-Pribić R, Petrović S, Tomić J. Childhood asthma and risk factors. Med Pregl 2010;63(78):516-21.

2. The Global Asthma Report 2014. Auckland, New Zealand: Global Asthma Network, 2014.

3. World Allergy Organization. White Book on Allergy. Milwaukee: World Allergy Organization, 2013.

4. Pearce N, Douwes J. The global epidemiology of asthma in children. Int $\mathrm{J}$ Tuberc Lung Dis 2006;10(2):125-32.

5. Domuz S, Domuz A, Petrović S. Prevalence and Comorbidity of Asthma, Allergic Rhinitis and Eczema among School Children in Republic of Srpska - Cross-Sectional Study. Srp Arh Celok Lek 2017 Jan-Feb;145(1-2):9-13.

6. Engelkes M, Janssens HM, de Ridder MA, de Jongste JC, Sturkenboom MC, Verhamme KM. Time trends in the incidence, prevalence and age at diagnosis of asthma in children. Pediatr Allergy Immunol 2015;26(4):367-74.

7. Lai CK, Beasley R, Crane J, Foliaki S, Shah J, Weiland $S$, et al. Global variation in the prevalence and severity of asthma symptoms: phase three of the International Study of Asthma and Allergies in Childhood (ISAAC). Thorax 2009;64(6):476-83.

8. Asher MI, Montefort S, Bjorksten B, Lai CK, Strachan DP, Weiland SK, et al. Worldwide time trends in the prevalence of symptoms of asthma, allergic rhinoconjunctivitis, and eczema in childhood: ISAAC Phases One and Three repeat multicountry cross-sectional surveys. Lancet 2006;368(9537):733-43.

9. Patel SP, Jarvelin MR, Little MP. Systematic review of worldwide variations of the prevalence of wheezing symptoms in children. Environ Health 2008;7:57.

10. Živković Z, Vukašinović Z, Cerović S, Radulović $\mathrm{S}$, Živanović S, Panić E, et al. Prevalence of childhood asthma and allergies in Serbia and Montenegro. World J Pediatr 2010;6(4):331-6.

11. Munivrana H, Vorko-Jović A, Munivrana S, Kursar M, Medlobi-Gluhak M, Vlahek P. The prevalence of allergic diseases among Croatian school children according to the ISAAC Phase One questionnaire. Medical Science Review 2007;13(11):CR505-CR9.

12. Vlaski E, Stavrik K, Seckova L, Isjanovska R, Kostovski A, Kimovska M. Prevalence and severity 
of asthma, allergic rhinitis and eczema in school children in Skopje (International Study of Asthma and Allergies in Childhood Phase 3). Macedonian Journal of Medicine 2005;51(1-2):12-23.

13. Engelkes M, Janssens HM, de Ridder MA, de Jongste JC, Sturkenboom MC, Verhamme KM. Time trends in the incidence, prevalence and age at diagnosis of asthma in children. Pediatr Allergy Immunol 2015;26(4):367-74.

14. Paul G, Brehm JM, Alcorn JF, Holguin F, Aujla SJ, Celedon JC. Vitamin D and asthma. Am J Respir Crit Care Med 2012;185(2):124-32.

15. De Marco R, Locatelli F, Sunyer J, Burney P. Differences in incidence of reported asthma related to age in men and women: a retrospective analysis of the data of the European Respiratory Health Survey. Am J Respir Crit Care Med 2000;162(1):68-74.

16. Postma DS. Gender differences in asthma development and progression. Gend Med 2007;4 Suppl B:S133-46.

17. Almqvist C, Worm M, Leynaert B. Impact of gender on asthma in childhood and adolescence: a GA2LEN review. Allergy 2008;63(1):47-57.

18. Fincham JE. Response rates and responsiveness for surveys, standards, and the Journal. Am J Pharm Educ 2008;72(2):43.

19. Johnson T, Owens L, editors. Survey response rate reporting in the professional literature. Nashville; American Association for Public Opinion Research, 2003.

ABSTRACT: Our study is the first one that used the international methodology for determining the prevalence of allergic diseases symptoms among school children. The aim of this study was to determine the prevalence and geographic variations of symptoms of allergic diseases in children on the territory of Republic of Srpska.

The study was conducted in the form of cross-sectional study and included 3,000 children from 13 primary schools. The prevalence of symptoms of allergic diseases is determined through questionnaires of the International Study of Asthma and Allergies in Children (ISAAC).

The prevalence of wheezing in the past 12 months in Republic of Srpska is 7.95\%, eczema is 5,01\% and symptoms of allergic rhinoconjunctivitis $12.71 \%$. Children aged 8 to 10 years have more often symptoms of asthma. The prevalence of symptoms of eczema and allergic rhinitis tends to increase up to 9 or 10. The age of the child, after which decline was observed in the incidence of these symptoms. The prevalence of symptoms of eczema and allergic rhinitis tends to increase up to 9 or 10 years of age of the child, after which decline was observed in the incidence of these symptoms.

Results of multicentric studies showed that developing countries, such as ours, are at more risk for a higher prevalence of symptoms of allergic diseases in children. Therefore, it is important to conduct epidemiological studies of the prevalence of these diseases, especially bearing in mind the impact of these diseases on the quality of life of children.

Keywords: asthma; eczema; allergic rhinitis; child; prevalence; cross-sectional studies.

doc. dr Sanela Domuz Vujnović

Visoka medicinska škola

Nikole Pašića 4 A

79101 Prijedor

telefon: 065/544-119

e-mail:drdomuz@gmail.com 